\author{
Jordan Necheva, \\ William W. Christieb, \\ Rafael Robainac, \\ Fernando de Diegoc, \\ Simeon Popova, \\ Kamen Stefanova \\ a Institute of Organic Chem- \\ istry with Centre of \\ Phytochemistry, Bulgarian \\ Acadamy of Science, \\ Sofia, Bulgaria \\ b The Scottish Crop \\ Resarch Institute, Inver- \\ gowrie, Dundee, Scotland \\ c University of Las Palmas, \\ Las Palmas, \\ Gran Canaria, Spain
}

\section{Lipid composition of the sponge Verongia aerophoba from the Canary Islands}

The fatty acid composition of the lipids from the sponge Verongia aerophoba was investigated and 60 acids were identified. Two of them were new and their structures were elucidated by gas chromatography-mass spectrometry. These acids were identified as 20-methylhexacosanoic and $\Delta 5,9,22$-nonacosatrienoic. Only 13 sterols were present, and aplysterol predominated. In the volatile fraction 13 compounds were identified, mainly fatty acids, their esters and hydrocarbons, while in the $\mathrm{n}$-butanol fraction we found mainly free fatty acids and free amino acids.

Keywords: Sponges, Verongia aerophoba, Demospongia, lipids, fatty acids, sterols, volatiles, polar compounds.

\section{Introduction}

Over the past 30 years, the marine sponges from the family Verongiidae (class Demospongia) have attracted growing interest because of their unique chemical composition and biological activity. Antibacterial and cytotoxic activities were proven for these compounds [1-5]. The sponges contain large quantities of $\mathrm{C}_{14}-\mathrm{C}_{30}$ fatty acids with branched and odd-chains [6, 7] and hydroxy-acids [8, 9]. The biosynthesis of these fatty acids occurs by chain elongation of monoenoic or branched precursors followed by desaturation [10]. The sterol composition was also unusual - besides small amounts of the widespread $\mathrm{C}_{27}-\mathrm{C}_{29}$ sterols with $\mathrm{C} 5$ double bond, which are accepted to be of dietary origin, the main sterols appeared to possess an unprecedented alkylation at C27. The main sterols appeared to be aplysterol (24,27-dimethyl-cholest-5-en-3 $\beta$ ol) and 24,27-dimethyl-cholesta-5,25(26)-dien-3ß-ol [1017]. The presence of demospongic acids in Verongia sponges, containing groups causing membrane disordering, is believed to be due to the need of the sponge for membranes possessing fluidity near the middle of the phospholipid bilayer. The additional 27-methyl group of aplysterol and analogous sterols probably causes the disordering of the phospholipid bilayer in the same region, and was evolved in response to this need [10]. There are no investigations on the lipid and sterol composition of Verongia aerophoba (old name Aplysina aerophoba) col-

Correspondence: Kamen Stefanov, Institute of Organic Chemistry with Centre of Phytochemistry, Bulgarian Academy of Science, ul. Acad. G. Bonchev, No 9, Sofia 1113, Bulgaria. Phone: +3592-9606-135, Fax: +3592-70-02-25; e-mail: kamen@orgchm.bas.bg lected in the Canary Islands and it is of interest to compare their composition with those of other Verongia sp., collected at different locations.

However, there are no investigations on some minor constituents of Verongia sp., as for example on volatile substances, isolated by steam distillation of the lipophilic extracts. It is known that the volatiles from plants often contain compounds with defensive functions such as attractants, repellents, antifeedants, insecticides, etc. [18, 19]. Till now research concerns almost entirely the volatiles from terrestrial plants, although there is a very limited number of publications on marine algae [20-22]. Some marine organisms use compounds that are largely insoluble in marine water as allelochemicals, and a part of these compounds are concentrated in the volatiles. Hydrocarbons and free fatty acids, which are common components of the volatiles, are used as chemical signals, for example as sex pheromones and allelopathic substances [23]. Also of interest are the polar compounds, which can be extracted with $n$-butanol from the water-alcohol layer after the extraction of the lipophilic compounds. The polar compounds are a significant part of the total extracts and often possess strong biological activity. The search for minor components of these different fractions could give valuable information about the marine food chains and about the chemotaxonomy of Verongia sp.

\section{Materials and methods}

\subsection{Isolation of lipophilic and polar compounds}

Sponges Verongia aerophoba were collected from the rocks of the Las Palmas shore at low tide in November 
1999. The samples were washed with fresh water and frozen at $-30^{\circ} \mathrm{C}$ for one week. After transportation to the laboratory, the sponges were extracted with a mixture of chloroform and methanol $(2: 1 \mathrm{v} / \mathrm{v})$, followed by filtration and addition of an equal volume of water. The emerging two layers were separated. The lower layer, containing the total lipids (lipophilic extract), was concentrated on a rotatory evaporator under vacuum at $60{ }^{\circ} \mathrm{C}$. The upper layer (polar fraction) was treated in the same way and extracted twice with $n$-butanol (butanol extracts). The yield of lipids was $14.9 \%$ of the dry weight of the sponges. The yield of the butanol extracts was $5.2 \%$ (from 27 sponges - total dry weight $9.89 \mathrm{~g}$ ).

A voucher specimen was deposited in the University of Las Palmas, Canary Islands, Spain.

\subsection{Preparation of the fatty acid methyl esters}

Part of the total lipid extract (45 mg) was transesterified with $15 \%$ acetyl chloride in methanol according to Christie [24]. The fatty acid methyl esters (FAME) were separated by preparative thin-layer chromatography (TLC) (plates $20 \times 20 \mathrm{~cm}$ silica gel Merck 60, layer $0.5 \mathrm{~mm}$ (Merck, Darmstadt, Germany), as mobile phase hexane-acetone 95:5 v/v was used).

\subsection{Catalytic hydrogenation}

Fatty acids methyl esters in methanol solution were subjected to catalytic hydrogenation with hydrogen gas and platinum oxide catalyst [25].

\subsection{Gas chromatography-mass spectrometry of fatty acid derivatives}

One part of the lipids was hydrolysed to result in free fatty acids, which were converted to the picolinyl esters [26] and to 4,4-dimethyloxazoline (DMOX) derivatives [27] by established methods. The derivatives were submitted to gas chromatography-mass spectrometry (GC-MS), with a Hewlett Packard 5890 Series II plus gas chromatograph attached to an HP model 5989 MS engine (Hewlett Packard, Palo Alto, CA, USA). The latter was applied in the electron impact mode at $70 \mathrm{eV}$ with a source temperature of $250{ }^{\circ} \mathrm{C}$. The GC was fitted with on-column injection, and equipped with a capillary column of fused silica coated with DB5-MSTM $(0.25 \mathrm{~mm} \times 30 \mathrm{~m}, 0.25 \mu \mathrm{m}$ film; J. \& W. Scientific, Folsom, CA, USA). After holding the temperature at $80^{\circ} \mathrm{C}$ for $3 \mathrm{~min}$, the column was temperature-programmed at $20^{\circ} \mathrm{C} / \mathrm{min}-160^{\circ} \mathrm{C}$, then at $4^{\circ} \mathrm{C} / \mathrm{min}$ $350^{\circ} \mathrm{C}$, where it was held for $20 \mathrm{~min}$. Helium was used as carrier gas.

\subsection{Isolation and analysis of sterols}

Another part of the lipophilic extract $(200 \mathrm{mg}$ ) was separated on a silica gel column $(20 \mathrm{~g})$ using mixtures of hexane and acetone in ascending polarity as eluent. The fractions, containing sterols as identified by the TLC were combined and purified by preparative TLC with hexaneacetone 9:1 as mobile phase. The sterols obtained were analysed by gas chromatography and by GC-MS under the same conditions as applied for the picolinyl esters above.

\subsection{Isolation and analyses of the volatile compounds}

One part of the lipophilic extract (555 mg) was subjected to a four-hour distillation-extraction in a Lickens-Nickerson apparatus [28]. The volatiles were extracted from the distillate with diethyl ether (yield: $146 \mathrm{mg}$ ) and investigated by analytical GC-MS (Hewlett Packard $6890+\mathrm{MS}$ 5973 with a capillary column HP5-MS, $30 \mathrm{~m} \times 0.25 \mathrm{~mm}$, $0.25 \mu \mathrm{m}$ film thickness). The temperature was programmed to raise from $40-280{ }^{\circ} \mathrm{C}$ at a rate of $6{ }^{\circ} \mathrm{C} / \mathrm{min}$. Helium was used as a carrier gas.

\subsection{Isolation and analyses of the n-butanol fraction}

The n-butanol fraction was isolated as described above. Part of it $(5 \mathrm{mg})$ was dissolved in $50 \mu \mathrm{l}$ pyridine, and $75 \mu \mathrm{l}$ of bis-(trimethylsilyl)-trifluoroacetamide (BSTFA) were added. The mixture was heated to $80{ }^{\circ} \mathrm{C}$ for $30 \mathrm{~min}$ and analysed by GC-MS on the system described above, but equipped with a capillary column HP-5 (23 $\mathrm{m} \times 0.2 \mathrm{~mm}$, $0.5 \mu \mathrm{m}$ film thickness). Helium was used as a carrier gas with a temperature programme $100-315^{\circ} \mathrm{C}$ at $5^{\circ} \mathrm{C} / \mathrm{min}$ and a 10-min hold.

\section{Results and discussion}

\subsection{Analysis of the fatty acids}

The GC-analysis of the FAME indicated that at least 60 different FA are present in Verongia aerophoba (Tab. 1).

The sponges from family Verongiidae are unique in their diversity of FA with a generally high level of long-, unsaturated, branched, and odd-chains [6, 29]. The sample investigated by us also contained significant amounts of branched and unsaturated FA. The main FA were palmitic, i-methyl-tetradecanoic, $\Delta 5,9,21$-octacosatrienoic and 22-methyl- $\Delta 5,9$-octacosadienoic acids. The last two acids were first identified in the sponge Verongia thiona from California [6]. Two other acids, 20-methyl-hexacosanoic and $\Delta 5,9,22$-nonacosatrienoic, have to the best of our knowledge not been found previously in sponges and any marine sources. 
Tab. 1. Constituent fatty acids of lipids isolated from the sponge Verongia aerophoba.

\begin{tabular}{|c|c|c|}
\hline Fatty acid & Retention time [min] & {$[w t-\%]^{\dagger}$} \\
\hline i-methylundecanoic (i-Me-C11:0) & 33.27 & 0.1 \\
\hline i-methyldodecanoic (i-Me-C12:0) & 37.24 & 0.2 \\
\hline tetradecanoic (C14:0) & 38.75 & 1.1 \\
\hline ? & 40.51 & 0.4 \\
\hline i-methyltetradecanoic (i-Me-C14:0) & 41.48 & 7.1 \\
\hline ai-methyltetradecanoic (ai-Me-C14:0) & 41.74 & 3.0 \\
\hline i-methylpentadecanoic (i-Me-C15:0) & 42.05 & 0.4 \\
\hline pentadecanoic (C15:0) & 42.68 & 1.2 \\
\hline ? & 44.25 & 0.8 \\
\hline$\Delta 9$-hexadecenoic $(\Delta 9-C 16: 1)$ & 45.90 & 5.7 \\
\hline$\Delta 11$-hexadecenoic $(\Delta 11-\mathrm{C} 16: 1)$ & 46.17 & 1.3 \\
\hline hexadecanoic (C16:0) & 46.76 & 7.6 \\
\hline branched hexadecenoic ? & 46.94 & 0.5 \\
\hline i-methyl-9-hexadecenoic (i-Me- $\Delta 9-\mathrm{C} 16: 1$ ) & 48.11 & 6.7 \\
\hline 10-methylhexadecanoic (10-Me-C16:0) & 48.38 & 1.3 \\
\hline i-methylhexadecanoic (i-Me-C16:0) & 48.82 & 2.4 \\
\hline ai-methylhexadecanoic (ai-Me-C16:0) & 49.19 & 3.4 \\
\hline$\Delta 9$-heptadecenoic $(\Delta 9-C 17: 1)$ & 49.27 & 0.2 \\
\hline 9,10-cycloprpopyl-hexadecanoic (9,10-cyclopropyl C16) & 49.61 & 0.4 \\
\hline heptadecanoic $(\mathrm{C} 17: 0)$ & 50.14 & 1.4 \\
\hline phytanic acid & 51.57 & 2.3 \\
\hline$\Delta 5,9$-octadecadienoic $(\Delta 5,9-C 18: 2)$ & 51.88 & 2.2 \\
\hline$\Delta 9,12$-octadecadienoic $(\Delta 9,12-C 18: 2)$ & 52.51 & 0.3 \\
\hline$\Delta 9$-octadecenoic $(\Delta 9-C 18: 1)$ & 52.76 & 1.2 \\
\hline$\Delta 11$-octadecenoic $(\Delta 11-C 18: 1)$ & 53.18 & 3.9 \\
\hline octadecanoic (C18:0) & 53.80 & 3.8 \\
\hline 11-methyloctadecanoic (11-Me-C18:0) & 55.05 & 6.7 \\
\hline$\Delta 11$-nonadecenoic $(\Delta 11-\mathrm{C} 19: 1)$ & 55.45 & 0.6 \\
\hline 11,12-cyclopropyloctadecanoic (11,12-cyclopropyl C18) & 56.82 & 1.9 \\
\hline nonadecanoic (C19:0) & 57.14 & 0.6 \\
\hline$\Delta 5,8,11,14$-eicosatetraenoic $(\Delta 5,8,11,14-\mathrm{C} 20: 4)$ & 57.67 & 0.8 \\
\hline$\Delta 5,8,11,14,17$-eicosapentaenoic $(\Delta 5,8,11,14,17-\mathrm{C} 20: 5)$ & 57.89 & 0.3 \\
\hline$\Delta 11,14$-eicosadienoic $(\Delta 11,14-\mathrm{C} 20: 2)$ & 59.42 & 0.3 \\
\hline eicosanoic (C20:0) & 60.50 & 1.0 \\
\hline 14-methyleicosanoic (14-Me-C20:0) & 61.70 & 0.5 \\
\hline i-methyleicosanoic (i-Me-C20:0) & 62.50 & 0.6 \\
\hline ai-methyleicosanoic (ai-Me-C20:0) & 62.83 & 1.0 \\
\hline heneicosanoic $(\mathrm{C} 21: 0)$ & 63.69 & 0.3 \\
\hline$\Delta 5,9$-docosadienoic $(\Delta 5,9-C 22: 2)$ & 64.95 & 0.1 \\
\hline$\Delta 15$-docosaenoic $(\Delta 15-\mathrm{C} 22: 1)$ & 66.29 & 0.1 \\
\hline docosanoic (C22:0) & 66.82 & 0.2 \\
\hline$\Delta 5,9$-tricosadienoic $(\Delta 5,9-C 23: 2)$ & 67.20 & 0.1 \\
\hline$\Delta 5,9$-tetracosadienoic $(\Delta 5,9-C 24: 2)$ & 69.93 & 0.1 \\
\hline tetracosanoic $(\mathrm{C} 24: 0)$ & 72.84 & 0.1 \\
\hline 18-methyltetracosanoic (18-Me-C24:0) & 73.98 & 0.3 \\
\hline i-methyltetracosanoic (i-Me-C24:0) & 74.64 & 0.1 \\
\hline ai-methyltetracosanoic (ai-Me-C24:0) & 74.97 & 0.2 \\
\hline$\Delta 5,9$-hexacosadienoic $(\Delta 5,9-\mathrm{C} 26: 2)$ & 76.93 & 0.3 \\
\hline$\Delta 5,9$-heptacosadienoic $(\Delta 5,9-C 27: 2)$ & 78.00 & 0.9 \\
\hline heptacosaenoic (C27:1) & 78.52 & 0.1 \\
\hline 20-methylhexacosanoic (20-Me-C26:0) & 79.63 & 0.6 \\
\hline$\Delta 5,9$-octacosadienoic $(\Delta 5,9-C 28: 2)$ & 80.91 & 0.3 \\
\hline$\Delta 5,9,21$-octacosatrienoic $(\Delta 5,9,21-\mathrm{C} 28: 3)$ & 82.40 & 5.5 \\
\hline 22-methyl- $\Delta 5,9$-octacosadienoic (22-Me- $\Delta 5,9-\mathrm{C} 28: 2)$ & 83.86 & 8.3 \\
\hline$\Delta 5,9$, ?-nonacosatrienoic $(\Delta 5,9, ?-\mathrm{C} 29: 3)$ & 84.87 & 0.4 \\
\hline$\Delta 5,9,22$-nonacosatrienoic $(\Delta 5,9,22-\mathrm{C} 29: 3) \ddagger$ & 85.12 & 0.8 \\
\hline$\Delta 5,9,23$-triacontanotrienoic $(\Delta 5,9,23-\mathrm{C} 30: 3)$ & 87.82 & 7.3 \\
\hline$\Delta 5,9$-untriacontanodienoic $(\Delta 5,9-\mathrm{C} 31: 2)$ & 88.66 & 0.7 \\
\hline
\end{tabular}

† Triplicate values for methyl esters in standard mixture by gas chromatographic analysis varied within $12 \%$ for minor components $(<5 \%$ content) and within $5 \%$ for the others. $\neq$ Not previously recognised in nature. 
20-methyl-hexacosanoic acid may be an intermediate in the biosynthetic route to the demospongic acid [6]:

10-Me-C16:0 $\rightarrow$ 20-Me-C26:0 $\rightarrow$ 22-Me-C28:0 $\rightarrow$ 22-Me$\Delta 9-\mathrm{C} 28: 1 \rightarrow$ 22-Me- $\Delta 5,9-\mathrm{C} 28: 2$

10-Methyl-palmitic acid is known to occur in Mycobacteria [30], Staphylococcus aureus [31] and Microbispora parva [32]. The similarity between the composition of the midchain branching pattern of fatty acids in Verongia aerophoba and in bacteria suggests the presence of bacteria in this sponge.

Samples were analysed by GC-MS in the form of various derivatives before and after catalytic hydrogenation to simplify the chromatograms and make it easier to locate the branch points.

The mass spectra of the picolinyl ester and DMOX derivatives of 20-Me-C26:0 acid are shown in Fig. 1. In the spectrum of the picolinyl ester (upper), the gap of $28 \mathrm{amu}$ between $\mathrm{m} / \mathrm{z}=388$ and 416 located the methyl branch [33], which was confirmed by a similar gap between $\mathrm{m} / \mathrm{z}=$ 350 and 378 in the spectrum of the DMOX derivative (lower) [34]. The mass spectrum of the methyl ester derivative (not illustrated) was consistent with this interpretation.

The second novel fatty acid ( $\Delta 5,9,22$-nonacosatrienoic) was also identified from the mass spectra of its picolinyl ester and DMOX derivatives (Fig. 2). The mass spectrum of the picolinyl ester (upper) has a molecular ion at $m / z=523$, and a characteristic ion for a bis-methyleneinterrupted double bond system at $m / z=219$, due to the cleavage between carbons 7 and 8 [25, 35, 36]. A gap of 26 amu between $\mathrm{m} / \mathrm{z}=232$ and 258 confirms that there is a double bond in position 9. Regular series of $14 \mathrm{amu}$ apart on either side of these features confirmed that no further unsaturated centres were present until a gap of 26 amu appeared between $\mathrm{m} / \mathrm{z}=412$ and 438 , as expected for a double bond in position 22 [33]. The structure was supported by the spectrum of the DMOX derivative (Fig. 2, lower). In this instance, the molecular ion was at $m / z=485$, and the 5,9-double bond system was defined by a characteristic ion at $m / z=180$ [27]. The isolated double bond in position 22 was identified by a gap of $12 \mathrm{amu}$ between $m / z=374$ and 386 . The data from the silver ion chromatography and the retention time of chromatograms confirm the cis-configuration of all double bonds.

An isomeric $\Delta 5,9,23$-nonacosatrienoic acid was isolated from the sponge Verongia thiona from Seal Point, La Jolla, California, USA [6] and from an endemic sponge Lubomirskia baicalensis from Lake Baikal, Russia [37].

\subsection{Investigation of the sterols}

Sterols were purified by consecutive column and TLC on silica gel. Their analysis was performed by GC, GC-MS and ${ }^{1} \mathrm{H}$ nuclear magnetic resonance (NMR) spectroscopy. The results obtained are summarised in Tab. 2 .
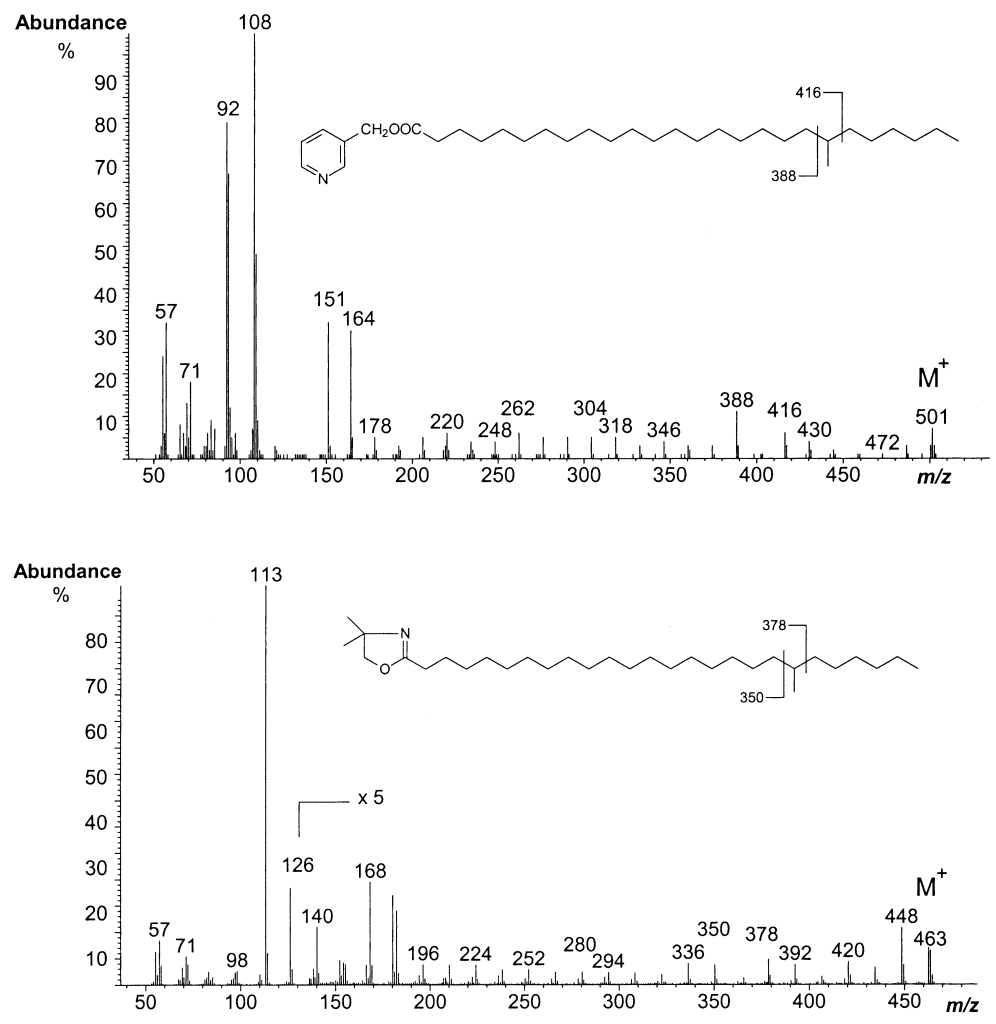

Fig. 1. Mass-spectrum of 20-methyl-C26:0 acid as a picolinyl ester (top) and DMOX-derivative (bottom). 

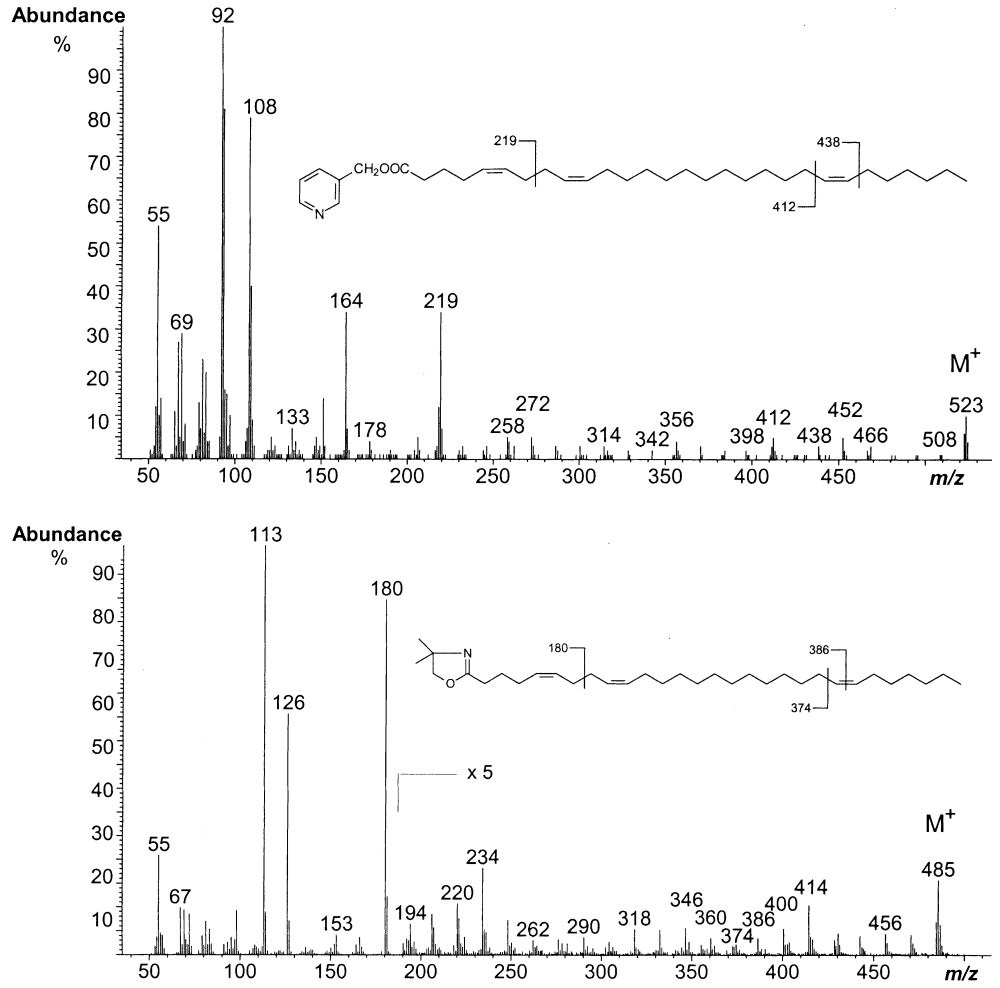

Fig. 2. Mass-spectrum of 5,9,22-C29:3 acid as a picolinyl ester (top) and DMOX-derivative (bottom).
We compared the sterol composition of $V$. aerophoba with the data on the sterol content in a closely related sponge, namely Verongia thiona [6]. It appeared that in all cases 24,27 -dimethyl-cholest-5-en-3 $\beta$-ol is the main sterol, accompanied by significant amounts of 24,27-dimethyl-

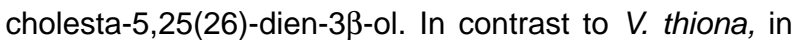

Tab. 2. Composition of total sterols isolated from Verongia aerophoba.

\begin{tabular}{|c|c|}
\hline Sterol & {$[w t-\%]^{\dagger}$} \\
\hline \multicolumn{2}{|l|}{ (22Z) cholesta-5,22-dien-3 $\beta$-ol or } \\
\hline occelasterol & $0.3 \pm 0.02$ \\
\hline $\pm 22 E)$ cholesta-5,22-dien-3 $\beta$-ol & $1.8 \pm 0.1$ \\
\hline cholest-5-en-3 $\beta$-ol & $10.3 \pm 0.8$ \\
\hline 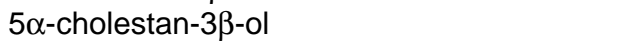 & $0.5 \pm 0.04$ \\
\hline 24-methyl-cholesta-5,22-dien-3 $\beta$-ol & $3.9 \pm 0.3$ \\
\hline \multicolumn{2}{|l|}{ 24-methyl-cholesta-5,25-dien-3 $\beta$-ol } \\
\hline \pm codisterol) & $1.4 \pm 0.1$ \\
\hline 24-methyl-cholest-5-en-3 $\beta$-ol & $3.5 \pm 0.3$ \\
\hline 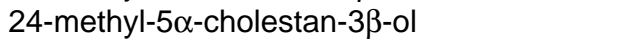 & $<0.1$ \\
\hline 24-ethyl-cholesta-5,22-dien-3 $\beta$-ol & $2.4 \pm 0.2$ \\
\hline \multicolumn{2}{|l|}{ 24-ethyl-cholesta-5,25-dien-3 $\beta$-ol } \\
\hline \pm clerosterol) & $2.4 \pm 0.2$ \\
\hline \multicolumn{2}{|c|}{ 24,27-dimethyl-cholesta-5,25(26)-dien-3ß-ol } \\
\hline (25(26)-dehydroaplysterol) & $31.8 \pm 2.5$ \\
\hline \multicolumn{2}{|l|}{ 24,27-dimethyl-cholest-5-en-3 $\beta$-ol } \\
\hline 24-propyl-cholesta-5,24(28)-dien-3 $\beta$-ol & $1.2 \pm 0.1$ \\
\hline
\end{tabular}

${ }^{\dagger}$ wt- $\%$ of total sterols \pm SD from three parallel GC analyses. the $V$. aerophoba investigated by us the differences in the concentrations of both of these sterols are much smaller (40\% and $32 \%$ against $53 \%$ and $7 \%$ in $\mathrm{V}$. thiona), which shows that there are some differences in the rate of their metabolism.

(22Z)-cholesta-5,22-dien-3 $\beta$-ol and/or occelasterol have not been found earlier in Verongia sp. Here, we found low concentrations of sterols with identical RT values and mass spectra to both of these sterols, which could not be distinguished by GC and mass spectra. The complete absence of $\mathrm{C}_{26}$ sterols in both Verongia species was in agreement with our earlier hypothesis that invertebrates in tropical waters do not contain such sterols and their concentration increases with the decrease of the water temperature [38]. A series of minor sterols with a C5 double bond were present in all investigated Verongiasp. and were probably of dietary origin. In contrast to most of the marine invertebrates, a significant number of sterols in $\mathrm{V}$. aerophoba contained a C25 double bond and stanols were present in very low concentrations.

\subsection{Investigations of the volatiles}

Volatile components of the sponge were isolated by distillation-extraction and investigated by GC-MS. For identification, comparisons were made of the spectra obtained with those of authentic samples. When the spectra of isomers showed insignificant differences, GC retention times 
Tab. 3. Composition of volatiles from Verongia aerophoba.

\begin{tabular}{lc}
\hline Component & {$[\mathrm{wt}-\%]^{\dagger}$} \\
\hline Acids & \\
octanoic acid (C8:0) & 0.3 \\
pentadecanoic acid (C15:0) & 2.1 \\
hexadecenoic acid (C16:1) & 0.9 \\
$\quad$ hexadecanoic acid (C16:0) & 1.1 \\
Hydrocarbons & \\
tetradecane (C14:0) & 0.7 \\
hexadecane (C16:0) & 3.8 \\
heptadecane (C17:0) & 1.8 \\
octadecane (C18:0) & 1.3 \\
heneicosane (C21:0) & 0.8 \\
docosane (C22:0) & 1.1 \\
Alcohols & \\
benzyl alcohol & 0.3 \\
Esters & \\
isopropylacetate & 4.4 \\
Ketones & \\
2-undecanone & 0.3 \\
\hline †The determination is semiquantitative. Only identified com- \\
pounds are reported.
\end{tabular}

were used for additional identification. The results obtained are presented in Tab. 3 . It is evident that the composition of the volatiles is relatively simple. Similarly to some other invertebrates (unpublished results) the main components were fully saturated $n$-hydrocarbons from $\mathrm{C}_{14}-\mathrm{C}_{21}$. It is evident that, in contrast to plants and vertebrates, where saturated n-hydrocarbons with an odd number of carbon atoms predominate, here hydrocarbons with an even number of carbon atoms are in higher concentrations. This is characteristic for bacteria and can be explained by the known high concentration of bacteria in some sponges. This is in agreement with the high concentration of the free pentadecanoic acid obtained. The sponge may use the hydrocarbons, together with the free fatty acids identified by us, as chemical signals [23]. Isopropyl acetate has not been found earlier in marine organisms and we have no information on its functions.

\subsection{Investigations of the polar compounds in the $n$-butanol extract}

Polar compounds are concentrated in the n-butanol extract from the sponge. They appear as very complex mixtures, whose separation is a difficult task. For this reason we investigated the polar fractions by GC-MS. The volatility of the polar compounds is low and in order to make them suitable for GC-MS analysis we silylated the total butanol extract. The identification of the compounds was made by comparisons with the spectra of authentic sily-
Tab. 4. Composition of the n-butanol extract from Verongia aerophoba.

\begin{tabular}{lc}
\hline Component & ${\text { [wt-\% }]^{\dagger}}^{\dagger}$ \\
\hline Acids & \\
pentadecanoic acid (C15:0) & 0.2 \\
palmitelaidic acid & 0.2 \\
hexadecanoic acid (C16:0) & 0.4 \\
H3PO4 & $<0.1$ \\
Alcohols & \\
glycol & 0.1 \\
glycerol & 0.1 \\
N-containing & \\
2,4-di-OH-pyrimidine & 0.2 \\
2,4-di-OH-pyrimidinedione & 0.3 \\
6-hydroxy-9H-purine & 0.2 \\
2,6-dihydroxy-9H-purine & 0.2 \\
alanine & $<0.1$ \\
glycine & 0.2 \\
Sterols & \\
cholesterol & \\
brassicasterol & 0.5 \\
25-dehydroaplysterol & 0.1 \\
aplysterol & 1.4 \\
\hline
\end{tabular}

${ }_{\dagger}$ see Tab. 3.

lated samples and in cases when there were negligible differences in the spectra of some of the isomers, we compared also the GC retention times. The results obtained are presented in Tab. 4.

In the polar fractions from Verongia aerophoba, we found five groups of compounds. Free acids appeared to be natural products and not artifacts, produced by hydrolysis of lipids through the extraction and purification process. The procedures for the isolation of the polar fraction, silylation and GC-MS investigation exclude the formation of artifacts. Four representatives of nucleotides were found, which is not characteristic for sponges. The main components of the polar fraction appeared to be brominated derivatives. All of them contain two bromine atoms and most have even molecular masses.

It must be mentioned that all Black Sea invertebrates and algae investigated until now contain significant amounts of free monosaccharides in the polar fractions, obtained by the same procedure. In the algae Padina pavonia from the Adriatic Sea we did not find free monosaccharides. The same was true for the Mediterranean sponge Ircinia muscarum (S. De Rosa et al., unpublished work) and for the sponge Chondrosia reniformis, collected at the same time and place as Verongia aerophoba. Now we found the same in Verongia aerophoba - no free monosaccharides were present. In all cases, the investigated organisms in- 
habit warmer waters and probably the temperature is the reason for the differences in sugar metabolism.

Of special interest is the identification of significant amounts of sterols in the polar fraction. According to the extraction procedure which we followed, sterols should be completely extracted with chloroform from the total extract. In the latter, we identified sterols, but significant amounts of sterols with the same relative concentrations as those from the chloroform extract were also identified in the n-butanol extract. Probably some amounts of sterols exist in sponges as unstable complexes with polar compounds (sugars, amino acids, etc.), which are not soluble in chloroform. They remained in the polar fraction, isolated by the $n$-butanol extraction and are probably decomposed by the silylation procedure, liberating TMSethers of sterols. This is the first case in which sterols were found in significant concentrations in the polar fraction. Recently in Chondrosia reniformis, we also found significant amount of sterols in the n-butanol fraction, obtained by the same procedure.

Both sponges grew together and were collected on the same day. This means that the compositions of the plankton and detritus in both places were identical, so that the differences in the chemical composition of the two sponges should depend on differences in the metabolism or on dietary requirements.

The differences in the fatty acid composition of the two sponges are significant as expected. These acids stem from the diet and are metabolised in the organisms; however, their composition depends on the requirements of the cell membranes, which are different in both sponges, due to their biodiversity. The situation in the sterol composition is analogous. Both sponges show similar compositions for the dietary sterols, whereas cholesterol is the main component, but in Chondrosia reniformis, dietary sterols do not undergo additional transformations, while in Verongia aerophoba the dietary sterols undergo alkylation at C27. It is evident that the differences obtained are due to differences in the cell wall composition, which is in agreement with the differences in the fatty acid composition.

The volatiles in both sponges did not show big differences. The main difference was the presence of significant amounts of methyl and ethyl esters of fatty acids in Chondrosia reniformis, which were absent in Verongia aerophoba. Evidently, the esterases were less active in the second sponge.

In the volatiles from Chondrosia reniformis we found some unambiguously defensive compounds, mainly phenols, which were absent in Verongia aerophoba. Probably this was due to the presence in the second sponge of brominated compounds, which could serve as defensive agents, so there was no need of more defensive compounds in this sponge.

The compositions of the polar compounds in both sponges differ more significantly. There was much more variability in the polar components of Chondrosia reniformis. In this sponge, free fatty acids were identified in the polar fraction, while in Verongia aerophoba we identified only three free fatty acids. The same was the case for the free amino acids. Nucleotides in both sponges had similar compositions, which might be connected to similarities in their metabolism.

The polar complexes of sterols in both sponges proposed above had analogous sterol composition to the fractions of free sterols, which differed in both sponges. It was evident that these complexes were formed in the organism by the sponge itself, otherwise, if they came from the diet, they should have had identical composition in both sponges investigated.

Brominated compounds were discovered only in Verongia aerophoba and evidently, they were biosynthesised in the organism.

\section{Acknowledgements}

Partial support by the National Foundation for Scientific Research of Bulgaria (Contract X-1101), NATO Science fellowships (to KS) and by the Scottish Executive Rural Affairs Department is gratefully acknowledged.

\section{References}

[1] R. Teeyapant, H. Woerdenbag, P. Kreis, J. Hacker, V. Wray, L. Witte, P. Proksch: Antibiotic and cytotoxic activity of brominated compounds from the marine sponge Verongia aerophoba. Z. Naturforsch. 48c (1993a) 939-945.

[2] G. Cimino, S. De Rosa, S. De Stefano, R. Self, G. Sodano: The bromo-compounds of the true sponge Verongia aerophoba. Tetrahedron Lett. 24 (1983) 3029-3032.

[3] P. Ciminiello, C. Dell'Aversano, E. Fattorusso, S. Magno, L. Carrano, M. Pansini: Chemistry of Verongida sponges. VII. Bromo-compounds from the Caribbean sponge Aplysina archeri. Tetrahedron Lett. 52 (1996) 9863-9868.

[4] P. Ciminiello, C. Dell'Aversano, E. Fattorusso, S. Magno, M. Pansini: Chemistry of Verongida sponges. 9. Secondary metabolite composition of the Caribbean sponge Aplysina cauliformis. J. Nat. Prod. 62 (1999) 590-593.

[5] R. Teeyapant, P. Proksch: Biotransformation of brominated compounds in the marine sponge Verongia aerophoba-evidence for an induced chemical defence? Naturwissenschaften 80 (1993b) 369-370.

[6] R. Walkup, G. Jamieson, M. Ratcliff, C. Djerassi: Phospholipid studies of marine organisms: phospholipids, phospholipid-bound fatty acids and free sterols of the sponge Aplysina fistularis (Pallas) forma fulva (Pallas) (=Verongia thiona). 
Isolation and structure elucidation of unprecedented branched fatty acids. Lipids 16 (1981) 631-646.

[7] S. Imre, M. Acikkol: Free fatty acids composition of some marine invertebrates collected from Turkish waters. Istanbul Univ. Eczacilik Fak. Mecm. (English) 17 (1981) 202-207.

[8] N. Carballeira, F. Shalabi, V. Negron: 2-hydroxy fatty acids from marine sponges 2 . The phospholipid fatty acids of the Caribbean sponges Verongula gigantea and Aplysina archeri. Lipids 24 (1989) 229-232.

[9] N. Carballeira, A. Emiliano, J. Rodriguez, E. Reyes: Isolation and characterization of novel 2-hydroxy fatty acids from the phospholipids of the sponge Smenospongia aurea. Lipids 27 (1992) 681-685.

[10] M. Lawson, J. Thompson, C. Djerassi: Localization of longchain fatty acids and unconventional sterols in Spherulous cells of a marine sponge. Lipids 23 (1988) 1037-1048.

[11] C. Catalan, J. Thompson, W. Kokke, C. Djerassi: Biosynthetic studies of marine lipids-3: Experimental demonstration of the course of side chain extension in marine sterols. Tetrahedron Letters 41 (1985) 1073-1084.

[12] W. Kokke, C. Pak, W. Fenical, C. Djerassi: 137. minor and trace sterols in marine invertebrates. XII. Occurence of 24(R+S)-isopropenylcholesterol, 24(R+S)-methylcholesta5,25-dien-3B-ol, and 24(R+S)-methylcholesta-7,25-dien$3 \mathrm{~B}-\mathrm{ol}$ in the Caribbean sponge Verongia cauliformis. Helvetica Chimica Acta 62 (1979) Nr. 137.

[13] R. Teeyapant, P. Kreis, V. Wray, L. Witte, P. Proksch: Brominated secondary compounds from the marine sponge Verongia aerophoba and the sponge feeding gastropod $T y$ lodina perversa. Z. Naturforsch. 48c (1993) 640-644.

[14] F. Cruz, L. Quijano, F. Gomez-Garibay, T. Rios: Brominated metabolites from sponge Aplysina (Verongia) thiona. J. Nat. Prod. 53 (1990) 543-548.

[15] N. Carballeira, C. Bou: The sterol composition of the marine sponge Aplysina (= Verongia) archeri: A comparativa study of the Verongidae. Comp. Biochem. Physiol. 93B (1989) 175-179.

[16] D. Sica, F. De Simone, E. Ramundo, F. Zollo: Sterols from some sponges. Biochem. Syst. Ecol. 6 (1978) 77-79.

[17] M. De Rosa, L. Minale, G. Sodano: Metabolism in Porifera. I. Biosythesis of fatty acids, sterols, and bromo-compounds by the sponge Verongia aerophoba. Comp. Biochem. Physiol. 45B (1973) 883-893.

[18] Y. Jiang, T. Ridsdill-Smith, E. Ghisalberti: The effect of volatile metabolites and lipid peroxidation on the aggregation of redlegged earth mites Halotigeus destructor (Acarina: penpanthalidae) on damaged cotyledons of subterranean clover. J. Chem. Ecol. 23 (1997) 163-174.

[19] S. Wang, E. Ghisalberti, J. Ridsdill-Smith: Volatiles from Trifolium as feeding deterents of reglegged earth mites. Phytochemistry 52 (1999) 601-605.

[20] Z. Kamenarska, S. Dimitrova-Konaklieva, C. Nicolova, A. Kujumgiev, K. Stefanov, S. Popov: Volatile components of the freshwater algae Spirogyra and Mougetia. Z. Naturforsch. 55 (2000) 495-499.

[21] G. Mahran, F. Soliman, E. El-Kashouy: Study of volative constituents of Dictyota dichotoma var. implexa. Indian Perfum. 37 (1993) 240-244.

[22] A. Gally, N. Yannovits, C. Poulos: The aroma volatiles from Cystoseira stricta var. Amentaceae: J. Essential Oil Res. 5 (1993) 27-32.
[23] M. Yasumoto, K. Mada, T. Ooi, T. Kusumi: New terpenoid components from the volatile oils of the soft corals Clavularia viridis and Sarcophyton acutangulum J. Nat. Prof. 63 (2000) 1534-1536.

[24] W. Christie: Gas Chromatography and Lipids, Oily Press, Ayr (UK) 1989.

[25] W. Christie: HPLC and GC-mass spectrometry in the analysis of fatty acids. In: Fats for the future. Ed. R. Cambie, Ellis Horwood Ltd. Chichester (England) 1989, pp. 335-344.

[26] M. Balazy, A. Nies: Characterization of epoxides of polyunsaturated fatty and GC-mass spectrometry in the analysis of fatty acids. In: Fats for the future. Ed. R. Cambie, Ellis Horwood Ltd. Chichester (England) 1989 pp. 335-344.

[27] L. Fay, U. Richli: Location of double bonds in polyunsaturated fatty acids by GC-MS after 4,4-dimethyloxazoline derivatization. J. Chromatogr. 541 (1991) 89-98.

[28] H. Hendriks, J. Geerts, Th. Malingre: The occurrence of valeranone and crypto-fauronol in the essential oil of Valeriana officinalis L. s.1. collected in the northern part of The Netherlands. Pharm. Weekblad, Sci. Edition. 116 (1981) 1316-1320.

[29] M. Lawson, P. Bergquist, R. Cambie: Fatty acid composition and the classification of the Porifera. Part 2. Fatty acid composition and the classification of the Porifera. Biochem. Syst. Ecol. 12 (1984) 375-393.

[30] I. Campbell, J. Naworal: Composition of the saturated and monounsaturated fatty acids of Mycobacterium phlei. J. Lipid Res. 10 (1969) 593-598.

[31] H. Egge, U. Murawski, W. Chatranon, F. Zilliken: The branched chain fatty acids of Staphylococcus aureus, a gas chromatographic-mass spectrometric analysis. Z. Naturforsch. B26 (1971) 893-901.

[32] A. Ballio, S. Barcellona: Identification of 10-methyl branched fatty acids in Microbispora parva by combined gas chromatography-mass spectrometry. Gazz. Chim. Ita. 101 (1971) 635-636.

[33] D. Harvey: Picolinyl esters as derivatives for the structural determination of long chain branched and unsaturated fatty acids. Biomed. Mass Spectrom. 9 (1982) 33-38.

[34] Q. Yu, B. Liu, J. Zhang, Z. Huang: Location of methyl branches in fatty acids: Fatty acids in uropygial secretion of Shanghai ducks by GC-MS of 4,4-dimethyloxazoline derivatives. Lipids 23 (1998) 804-810.

[35] W. Christie, E. Brechany, K. Stefanov, S. Popov: The fatty acids of the sponge Dysidea fragilis from the Black Sea. Lipids 27 (1992) 640-644.

[36] Y. Joh, I. Elenkov, K. Stefanov, S. Popov, G. Dobson, W. Christie: Novel di-, tri- and tetraenoic fatty acids with bismethylene-interrupted double bond systems from the sponge Haliclona cinerea. Lipids 32 (1997) 13-17.

[37] V. Dembitsky, T. Rezanka, A. Kashin: Comparative study of the endemic freshwater fauna of Lake Baikal-VI. Unusual fatty acids and lipid composition of the endemic sponge Lubomirskia baicalensis and its amphipod crustacean parasite Brandtia (Spinacanthus) parasitica. Comp. Biochem. Physiol. 109B (1994) 415-426.

[38] Ts. Milkova, S. Popov, N. Marekov: Sterols from Black Sea invertebrates - I. Sterols from Scyphozoa and Anthozoa (Coelenterata). Comp. Biochem. Physiol. 67B (1980) 633638.

[Received: April 17, 2002; accepted: September 18, 2002] 